\title{
A Multi-Objective Approach for Improving Technical Factors of Distribution Networks Considering Uncertainties in Loads and Wind Turbines
}

\author{
R. Eslami ${ }^{1 *}$, B. Eyvazi ${ }^{2}$, M. H. Soveyzi ${ }^{2}$, S. A. Hosseini ${ }^{3}$ and S. Taherkhani Aghaei ${ }^{2}$ \\ 'Department of Electrical Engineering, Sahand University of Technology, New Sahand Town, Tabriz, Iran; \\ reza.eslami@aut.ac.ir \\ ${ }^{2}$ Department of Electrical Engineering, Ekbatan Institute of Higher Education, Qazvin, Iran; \\ bab.eyvazi@gmail.com,m.h.soveyzi@gmail.com, siyavash.taherkhani@gmail.com \\ ${ }^{3}$ Department of Electrical Engineering, Golpayegan University of Technology, Isfahan, Iran; \\ amirhoseini.1365@aut.ac.ir
}

\begin{abstract}
Objectives: Objectives of this paper are to achieve decreasing power losses, maintaining permissible voltage profiles in distribution networks and also considering the uncertainties of network Components like loads and wind turbines. Methods/ Statistical Analysis: A new method is proposed for Distribution Feeder Reconfiguration (DFR) and capacitor placement considering Wind Turbine (WT) based on an improved reconfiguration technique. The employed DFR method is based on a single loop reconfiguration method which selects the optimal branch in each loop to achieve maximum loss reduction. Moreover, sequence of loops selection is optimized by using an optimization algorithm. Findings: A joint optimization algorithm has been proposed for combination of the capacitor placement and the improved network reconfiguration. This is due to the inherent coupling relationship between these methods, and therefore, simultaneous implementation of them is more effective than considering them separately. For more practical application of the proposed method, stochastic nature of loads and wind turbine generators of the network have been considered. Teaching-Learning Based Optimization (TLBO) algorithm has been employed for the proposed joint optimization problem and its results have been compared to the PSO and GA. The objective function has been proposed for minimizing the total cost due to capacitor placement and energy losses during 2 years with considering the constraints of bus voltages and the current carrying capacity of conductors. The obtained results confirmed the effectiveness of the proposed method. Application/Improvements: Simultaneous implementation of capacitor placement and reconfiguration method, considering stochastic nature of network and also employing TLBO algorithm for the proposed optimization problem.
\end{abstract}

Keywords: Load and Technical Improvement, Distribution Network, Uncertainty, Wind Turbine

\section{Introduction}

Nowadays the concern about energy shortage, economic features of fuel saving and also, environmental pollution problems increase interests in using of renewable energy resources ${ }^{1-3}$. Wind turbine is one of the major ways to generate electrical energy from renewable resources which converts the flowing wind energy into electrical energy. Distribution Feeder Reconfiguration (DFR) problem is one of the most important problems in distribution systems which could be affected by WTs ${ }^{4,5}$.

${ }^{*}$ Author for correspondence 
Electrical power losses exist in different parts of power system from generation to the end users; however, contribution of distribution systems in power losses is greater than other parts. Two important approaches to reduce power losses in distribution systems are DFR and capacitor placement. In the DFR, optimal network topologies could be obtained using tie and sectionalizing switches which their mood assign the configuration of distribution network, so that, the radial structure of the network is preserved. Also, capacitor placement in distribution networks maximizes power loss reduction. Indeed, parallel capacitors not only reduce losses, but also enhance the voltage curve, power factor, and voltage stability of the system. The size and location of the capacitors determine the level of compensation. In order to access optimal configuration of distribution network and capacitor installation, numerous efforts have been carried out recently ${ }^{6-11}$. $\operatorname{In}^{12}$ a joint optimization process combining Minimum Nodal Voltage method $(\mathrm{MNV})$ and Genetic Algorithms (GA) is performed to rearrange the network configuration and solve capacitor placement problem, respectively. The effectiveness of simultaneously applying these strategies in reducing power dissipation is more that of each method alone ${ }^{12}$. The research done in ${ }^{13}$ presents an efficient algorithm for optimization of radial distribution systems dealt with by a joint strategy using a network reconfiguration and capacitor allocation method. This modified genetic algorithm-based approach remarkably saved the purchasing cost of new capacitor banks, decreased the computational burden and improved the quality of the configurations. $\mathrm{In}^{14}$ to optimize the capacitor placement, an Improved Adaptive Genetic Algorithm (IAGA) is employed. Meanwhile, for each genetic chromosome, a simplified branch exchange technique is developed to reach the optimal network topology. $\mathrm{In}^{15}$, the state of capacitors and branch exchange in each loop was effectively achieved employing the Ant Colony Search Algorithm (ACSA). However, the branch which must be opened in each loop is not still the optimal one in primary iterations. Moreover, $\mathrm{in}^{14}$, the branch to be opened at each loop was precisely analyzed using a simple method in all iterations of the GA, and it is unnecessary to calculate the power loss reductions of all possible branch exchanges in determining an optimal branch exchange.

The DFR method used in this paper is based on the single loop reconfiguration method illustrated in ${ }^{14}$. In this method, the branch to be opened is formulated by mathematical equations in single loop networks. The single loop reconfiguration method is carried out on the networks loops respectively, while the sequence of loops selection is highly effective to achieve optimal network configuration due to the maximum power loss reduction. The significant innovation of our DFR method is to optimize the sequence of loops for rearrangement by single loop reconfiguration method. In subsequent parts of the paper, we have proven the effect of loops selection sequence on power loss reduction by providing examples in the under studying distribution network. DFR and capacitor placement which affect the optimal configuration and the power losses, have not been simultaneously incorporated in distribution networks which has wind turbine generators, up to now. It's obvious that by simultaneous implementation of DFR and capacitor placement, the most optimal network configuration will be obtained. Consequently, in iterations of the proposed optimization algorithm, not only capacitor modes are selected, but the loops selection sequence also is determined. Finally, due to access to the optimal distribution network configuration for maximum loss reduction, a joint optimization algorithm is proposed for combining the reconfiguration method and capacitor placement in distribution network with WT units. In order to select the best sequence for loops and optimize the location and capacitors' values, a strong optimization algorithm is needed. In our work, Teaching-Learning Based Optimization (TLBO) algorithm is used, which is more efficient and recently developed ${ }^{16,17}$. Simulation results confirm the validity of this optimization algorithm.

In addition to above mentioned, the DFR problem could be affected by WT and loads uncertainty. In this paper, for modeling variation generation of WTs and loads, we have used a scenario-based approach for modeling the stochastic nature of WT and loads demand. To consider stochastic nature of wind speed and loads magnitudes, in this paper they are modeled by normal Probability Density Function (PDF). Consequently, a network scenario is obtained by roulette wheel mechanism which is applied to each load and WT as for their PDF. As can be illustrated in section 3, the stochastic trend in uncertainty of these parameters is simulated by creating scenarios which can be solved by deterministic methods. In order to experimentally verify the numerically-obtained 
results, the simulation data are simultaneously tested on a region of realistic distribution network in Karaj city in Iran.

\section{Proposed Reconfiguration Method}

In initial configuration of distribution networks there are some lines which are normally open due to keeping the radial topology of the network. These lines are switched off by a switch (connector switch). In order to improve the networks reliability, one of these lines enters into the circuit and prevents some loads disruption only when one of the lines switched off in the network.

As already mentioned, when these lines are connected, a loop is formed in the network. In this loop, by opening the circuit breakers of both sides of a line, network takes radial structure. In this part a method is introduced to determine the lines which should be disrupted in order to have the minimum power losses according to its radial structure.

\subsection{Reconfiguration Method for Single Loop}

$\mathrm{In}^{14}$ an efficient method is proposed to determine the optimal line which should leave the circuit in the single loop. For this, in Figure 1 it is assumed that branches $\{i, \ldots, n\}$ named to be the $U$ set and branches $\{j, \ldots, m\}$ named to be the $D$ set. In addition, $r_{K}$ is resistance of the branch associated with the switch $K$. A power equals to $P_{K}+Q_{K}$ be transmitted between two sets when the switch $K$ is turned off and a separator switch is turned on. It should be mentioned that the transferred power is a continuous variable which transfers from $U-D$.

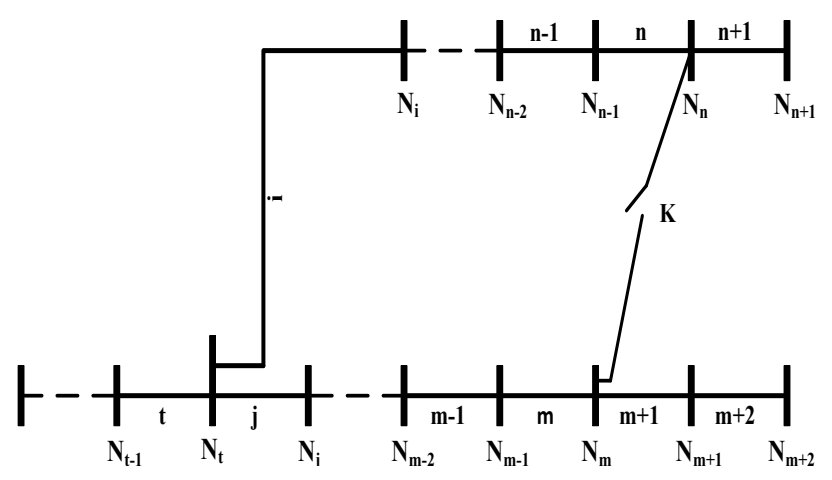

Figure 1. A distribution network with single loop.
After mentioned transformation the power loss reduction is obtained by Equation (1).

$$
\begin{aligned}
& P_{\text {loss }}^{\text {reduction }}=P_{\text {loss }}^{\text {before }}-P_{\text {loss }}^{\text {after }}= \\
& 2 \sum_{t \in U}\left[P_{t} P_{K}+Q_{t} Q_{K}\right] \cdot r_{t}-2 \sum_{t \in D}\left[P_{t} P_{K}+Q_{t} Q_{K}\right] \cdot r_{t}-\left(P_{K}^{2}+Q_{K}^{2}\right) \cdot r_{K}
\end{aligned}
$$

where $P_{\text {loss }}^{\text {reduction }}$ is power loss reduction, $P_{\text {loss }}^{\text {before }}$ is power loss before reconfiguration, and $P_{\text {loss }}^{\text {after }}$ is power loss after running reconfiguration method. $P_{t}$ and $Q_{t}$ are active and reactive power which are transmitted by lines.

In order to find the optimal power transmitted $P_{K}+Q_{K}$ that maximizes the power loss reduction, $P_{\text {loss }}^{\text {reduction }}$ partial derivation related to $P_{K}$ and $Q_{K}$ must be equal to zero using Equation (2).

$$
\left\{\begin{array}{l}
\frac{\partial P_{\text {loss }}^{\text {reduction }}}{\partial P_{K}}=0 \\
\frac{\partial P_{\text {loss }}^{\text {reduction }}}{\partial Q_{K}}=0
\end{array}\right.
$$

Considering the Equation (2), the optimal power to transmit between two sets is found according to Equation (3).

$$
\left\{\begin{array}{c}
P_{K}=\frac{\sum_{t \in U} P_{t} r_{t}-\sum_{t \in D} P_{t} r_{t}}{\sum_{t \in D \cup U} r_{t}+r_{K}} \\
Q_{K}=\frac{\sum_{t \in U} Q_{t} r_{t}-\sum_{t \in D} Q_{t} r_{t}}{\sum_{t \in D \cup U} r_{t}+r_{K}}
\end{array}\right.
$$

To specify the line with optimal power transmission, following constraints regarding transferred power symbol and quantity are defined.

If $P_{K}<\frac{P_{n}}{2}$ or $P_{K}<\frac{P_{m}}{2}$, real power loss in the loop already was minimum and the switch $K$ must be remain open.

If $P_{K}$ has a positive value, the optimal power is transferred from $U-D$. In set $U$ the branch that has the closest value to $P_{K}$ must be switched off.

Similarly, If $P_{K}$ has a negative value, the optimal power is transferred from $D$ to $U$. In this case, the branch in the set $D$ that has the closest value to $P_{K}$ must be switched off.

\subsection{Reconfiguration Method in Looped Distribution Networks}

Like one loop method which was presented in the previous section, connector switches are respectively chosen and 
the associated loop with each connector switch is distinguished and the line which should be opened is detected and opened. Such procedure is similarly done for the other connectors. The point which should be mentioned is that this method does not give the optimal lines to be opened, because selection order of connector switches is influenced in the lines which should be opened and consequently affects network configuration and its power loss.

At first, it is supposed that all the connector lines are open and then one connector is selected as the first connector and as shown in Figure 1,D and $U$ sets are determined. In the second step, a line that should be left from $U$ and $D$ sets is identified. This scheme is also done for the other connector lines. $\mathrm{In}^{14}$, connector switches are selected without any priority order, whereas, but connector lines selection order influences on some lines that must be departed from circuit and consequently affects network losses.

\section{Generating Stochastic Model for Network Loads and Wind Turbines}

\subsection{Generating Network Scenarios}

In this paper, to achieve a high accuracy in prediction of WTs and loads active power, their uncertainty is considered based on the forecast error of WTs and loads active power. Accordingly, a typical PDF has been employed to considering the forecast error of WTs and loads. The used continuous distribution function of forecast error of WTs and loads active power along with their discretization is shown in Figure 2. As shown in Figure 2, some intervals are on the zero mean and each of intervals is one forecast error of WTs or loads active power standard deviation, as presented in ${ }^{18}$. Finally, a roulette wheel mechanism is implemented to generate scenarios for a specified time ${ }^{19}$. The generated scenarios are selected on the basis of different forecast levels of WTs and loads and their obtained probabilities from their related PDF.

To this end, at first, the probabilities of different forecast levels of WTs and loads active power are normalized such that their summation becomes equal to one. Therefore, using roulette wheel mechanism, their scenario is formed. In this regards, as shown in Figure 3 , the interval of $[0,1]$ is allocated to the normalized probabilities. After that, random numbers are generated between 0 and 1. Each generated number is situated in the normalized probability range of forecast level in the roulette wheel (Figure 3). The selected interval is associated with a binary digit equal to one, and others become zero. After obtaining forecast level for all of the loads and wind speeds, a scenario of the network is produced.

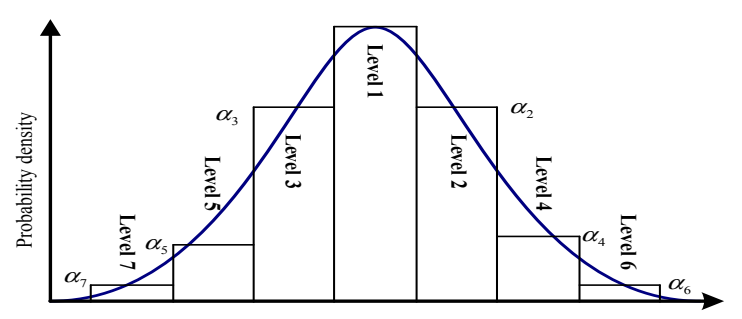

Figure 2. Discretization of PDF of load and wind speed error.

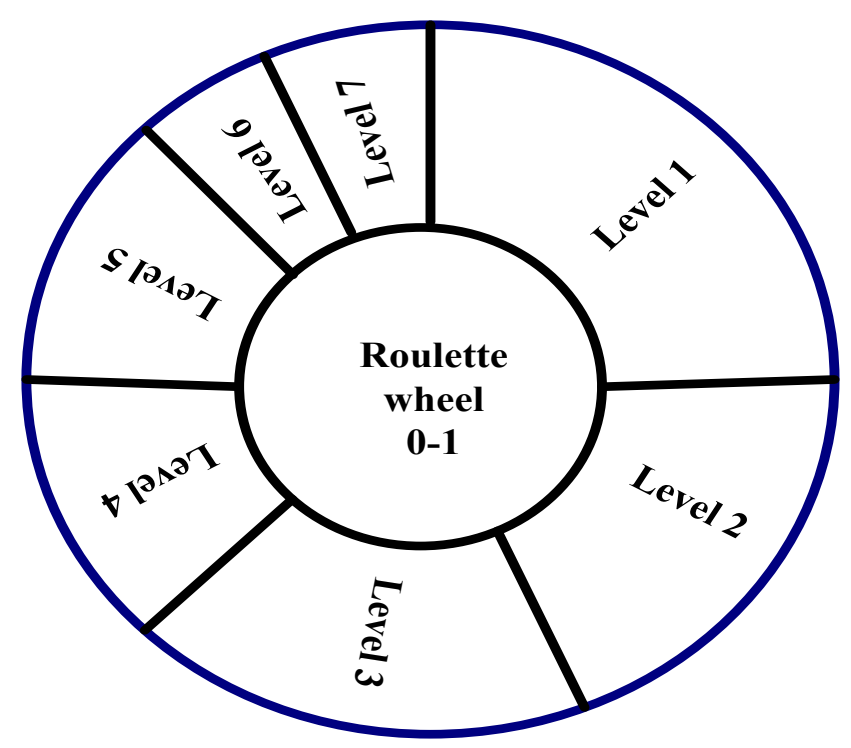

Figure 3. Roulette wheel selection.

A scenario is a vector that identifies the charge interval of all loads and WTs. Intended number of scenarios is produced by scenario generating scheme. Finally, the probability of all scenarios is calculated using Equation (4).

$P_{\text {Scenarion }}=\frac{\prod_{j=1}^{N_{W T}} \sum_{i=1}^{7} w_{n, i, j}^{W T} \cdot \alpha_{n, i, j} \cdot \prod_{m=1}^{N_{\text {load }}} \sum_{r=1}^{7} w_{n, r, m}^{\text {load }} \cdot \alpha_{n, r, m}}{\sum_{k=1}^{N_{\text {scen }}}\left(\prod_{j=1}^{N_{W T}} \sum_{i=1}^{7} w_{n, i, j}^{W T} \cdot \alpha_{n, i, j} \cdot \prod_{m=1}^{N_{\text {load }}} \sum_{r=1}^{7} w_{n, r, m}^{\text {load }} \cdot \alpha_{n, r, m}\right)}$ 
where $N_{W T}$ is the number of WTs, $N_{\text {load }}$ is the number of loads, $w_{n, i, j}^{W T}$ is binary parameter indicating whether the $i-t h$ wind interval of $j-t h \mathrm{WT}$ is selected in the nth scenario, and $N_{\text {scen }}$ is the number of scenarios.

\subsection{Reduction of the Scenarios}

A scenario reduction mechanism is employed to reduce the number of scenarios. On this basis, a good approximation of the system uncertain behavior is preserved ${ }^{20}$. For scenario reduction, the proposed mechanism has following steps:

Step 1: Construct the Kantorovich Distance $(K D)$ matrix ${ }^{21} . K D$ of each pair scenario is calculated by Equation (5).

$$
K D\left(\operatorname{Scen}^{i}, \operatorname{Scen}^{j}\right)=\left(\sum_{s=1}^{N_{L}+N_{W T}} P_{s}^{i}+P_{s}^{j}\right)^{0.5}
$$

Step 2: Determine the other nearest scenario to each scenario by calculated $K D$ in step 1 , and mark that in the $K D$ matrix $\left(\min \left\{K D\left(\right.\right.\right.$ Scen $^{i}$, Scen $\left.\left.\left.^{j}\right)\right\}\right)$.

Step 3: Compute the following term in Equation (6) for each pair of scenarios in the second step.

$$
k p^{i, j}=\min \left\{K D\left(\text { Scen }^{i}, \text { Scen }^{j}\right)\right\} \times P\left[\text { Scen }^{i}\right]
$$

Compare the $k p^{i, j}$ for all scenario pairs in the $K D$ matrix and locate, which pair has the minimum value. From this two scenarios, which one should be eliminated is chosen based on:

- Relative closeness to other scenarios.

- Small probability of occurrence.

Step 4: After eliminating one scenario, its probability is added to the probability of the closest scenario and the new $K D$ matrix is constructed.

Step 5: Go to step 2 and eliminate a scenario in iteration until the desired number of scenarios is obtained. In this paper, 10 representative scenarios at the end of iteration from the initial 1000 produced scenarios are considered.

\section{Optimization Method}

As mentioned, in a joint optimization problem, the purpose is to optimize several objectives simultaneously while some constraints should be met. In this paper, the proposed method of reconfiguration is combined with the capacitor placement by a joint optimization algorithm. The simplified branch exchange algorithm is used to find the optimal network structure (by considering the specified sequence of loops selection) for each instance of optimization algorithm in the each iteration of capacitor optimization algorithm. The mentioned optimization algorithm is Teaching-Learning Based Optimization (TLBO) algorithm.

The TLBO algorithm is based on the effect of a teacher performance on the learner's marks in a class ${ }^{16}$. An advantageous teacher produces a better mean for learner's marks in exam. Learners also learn from interaction with each other, which also helps them to leave and makes their marks better. In TLBO, different design variables are considered as different course subjects who presented to learners and the learners' result is considered as the 'fitness'. The best solution which is obtained so far is called the 'teacher level' of TLBO algorithm. The step-wise procedure for implementation of TLBO is divided into two parts. The first part is 'teacher phase' and the other part is 'learner phase'. The 'teacher phase' means making progress in students' knowledge by learning from the teacher and the obtained progress in students' knowledge by interaction between themselves is occurred in 'Learner phase ${ }^{16,17}$. The flow chart of TLBO operation is shown in Figure 4.

The main computational procedure of the joint optimization can be stated using a flowchart as shown in Figure 5. DIgSILENT Programming Language (DPL) is used to calculate the objective function of the paper. TLBO algorithm which is used to optimize capacitor placement and sequence of loops selection has been implemented by the MATLAB software. The capacitors mode and sequence of loops selection are produced by TLBO algorithm in MATLAB software based on the value of objective function and are recorded in a text file. DIgSILENT reads it as input data and applies them to the network (perform capacitor placement and apply the sequence of loops selection to the network for reconfiguration). Then, load flow calculation is run and the constraints are checked and the value of the objective function is calculated. Again, value of the objective function is given to MATLAB as input data via a text file. This procedure will be repeated until the result is converged. 


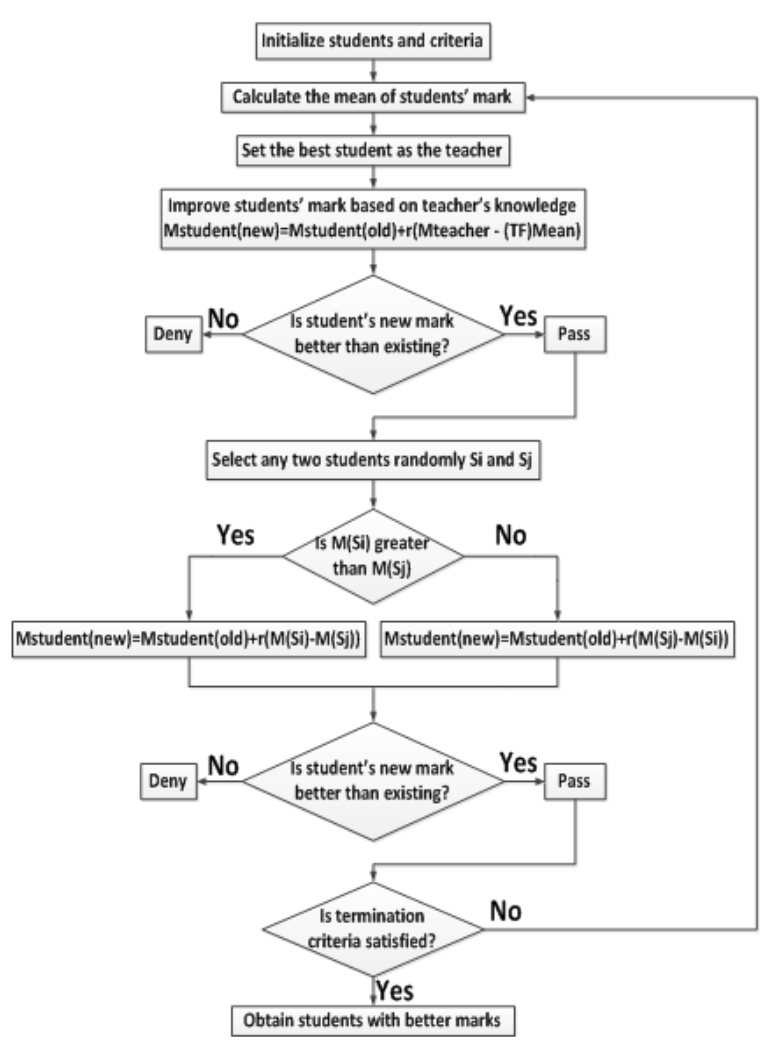

Figure 4. Flow chart of TLBO algorithm performance.

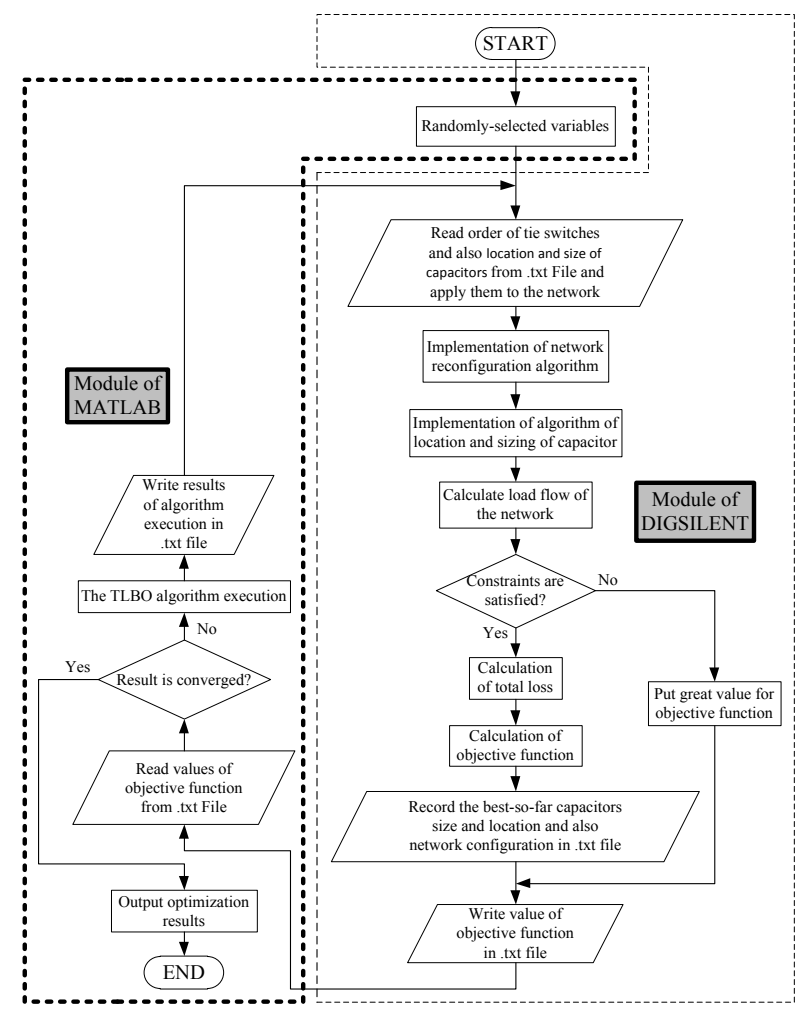

Figure 5. Flow chart of joint optimization algorithm.

\section{Simulation Results}

In this section, an 87 -Bus radial distribution system with WTs is considered to evaluate the proposed optimization approach. This distribution network is a real life distribution network of the city of Karaj in Iran which is shown in Figure 6. This distribution network has 13 tie switches. Total consumption of network is $18.88 \mathrm{MW}$ and 4.73 MVAr and active power loss of its' initial configuration is $504.094 \mathrm{~kW}$.

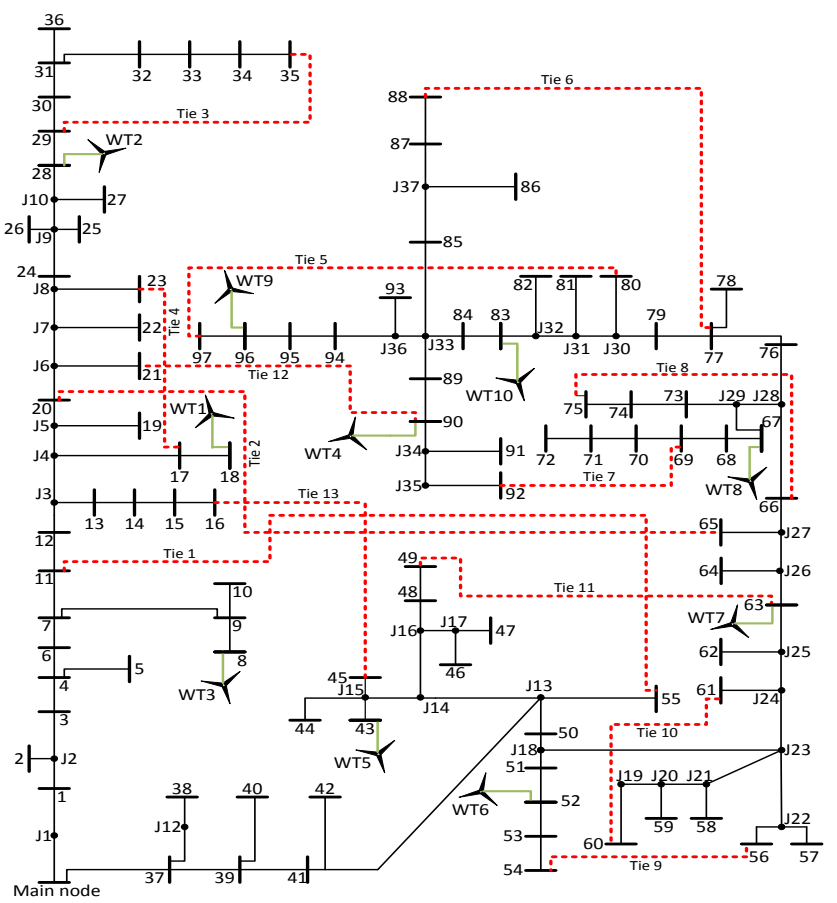

Figure 6. The study case distribution network.

The objective function of this paper is to minimize the total cost of network configuration which is formed by two portions: capacitor placement cost and energy losses cost. For this purpose, as we were sure that until the next year no changes will happen to the network, the network life is considered to be 2 years. The life time of capacitors which is used in this paper is supposed to be 20 years, so the cost of the installed capacitors is assumed to be $2 / 20$ of the capacitors purchase cost.

The sizes of the capacitors used in this paper have discontinuous magnitudes and have selected of 19 kinds of capacitors produced by IRAN TRANSFO factory which is presented in Equation 1.

Mathematical definition of the objective function proposed in this paper is shown in Equation (7). To 
Table 1. Information of capacitors used in this paper.

\begin{tabular}{|c|c|c|c|c|c|c|c|}
\hline Order & $\begin{array}{c}\text { Capacitor } \\
\text { capacity } \\
(\mathrm{kVAr})\end{array}$ & $\begin{array}{l}\text { Purchase cost } \\
\text { (\$) }\end{array}$ & $\begin{array}{l}\text { Installation } \\
\text { cost } \\
(\$)\end{array}$ & Order & $\begin{array}{c}\text { Capacitor } \\
\text { capacity } \\
(\mathrm{kVAr})\end{array}$ & $\begin{array}{c}\text { Purchase } \\
\text { cost } \\
(\$)\end{array}$ & $\begin{array}{c}\text { Installation } \\
\text { cost } \\
(\$)\end{array}$ \\
\hline 1 & 0 & 0 & 0 & 11 & 225 & 1508 & 139 \\
\hline 2 & 50 & 459 & 43 & 12 & 250 & 1629 & 139 \\
\hline 3 & 70 & 555 & 43 & 13 & 265 & 1925 & 155 \\
\hline 4 & 100 & 693 & 70 & 14 & 275 & 1967 & 182 \\
\hline 5 & 125 & 814 & 70 & 15 & 290 & 2263 & 198 \\
\hline 6 & 150 & 1152 & 112 & 16 & 300 & 2088 & 182 \\
\hline 7 & 170 & 1249 & 112 & 17 & 315 & 2384 & 198 \\
\hline 8 & 175 & 1273 & 112 & 18 & 325 & 2201 & 209 \\
\hline 9 & 195 & 1370 & 112 & 19 & 335 & 2480 & 198 \\
\hline 10 & 200 & 1387 & 139 & & & & \\
\hline
\end{tabular}

optimize this objective function, we consider constraints that are, limits on bus voltages and also capacity of current carrying of conductors as given in Equation (8) and Equation (9).

$$
\begin{gathered}
F_{\text {objective }}=2 \times 365 \times k_{\cos t}^{\text {energy }} \times E_{\text {Loss }}^{\text {daily }}+\sum\left(K_{\cos t}^{\text {installation }}+\frac{K_{\mathrm{cos} t}^{\text {purchase }}}{10}\right) \\
V_{\min } \leq\left|V_{i}\right| \leq V_{\max } \\
I_{L} \leq I_{\max }(L)
\end{gathered}
$$

where $k_{\cos t}^{\text {installation }}$ is cost of energy which is equal to $77.3 \$ / \mathrm{MWh}, E_{\text {Loss }}^{\text {daily }}$ is daily energy losses, $K_{\mathrm{cos} t}^{\text {installation }}$ is installation cost of capacitors, $K_{\text {cost }}^{\text {purchase }}$ is purchase cost of capacitors, $V_{\min }$ and $V_{\max }$ are minimum and maximum permissible bus voltages (equal to 0.95 and 1.05 p.u., respectively), and $I_{\max (L)}$ is current carrying capacity of line $L$.

\subsection{Stochastic Model for Loads and WTs}

In the case study of Figure 6, we consider stochastic model for loads and wind turbines. For modeling network loads and WTs generation based on the method which has been presented in section 3. Firstly, we create 1000 scenarios, and then we reduce these 1000 scenarios to 10 scenarios by the proposed scenario reduction method. The aggregated scenario can be obtained by considering probability of these 10 scenarios. Results of applying this stochastic model for active power generation of each ten WTs are

\begin{tabular}{|c|c|c|c|c|c|c|c|c|c|c|}
\hline & WT 1 & WT 2 & WT 3 & WT 4 & WT 5 & WT 6 & WT 7 & WT 8 & WT 9 & WT 10 \\
\hline Scenario 1 & 286 & 300 & 321.3 & 300 & 306.67 & 292.673 & 314.16 & 299.83 & 306.67 & 279.32 \\
\hline Scenario 2 & 286 & 307 & 314.1 & 307 & 293 & 286 & 307 & 286.16 & 286.16 & 286 \\
\hline Scenario 3 & 286 & 307 & 292.6 & 293 & 313.5 & 299.347 & 307 & 293 & 293 & 279.32 \\
\hline Scenario 4 & 279.32 & 300 & 307 & 307 & 293 & 292.673 & 307 & 293 & 293 & 286 \\
\hline Scenario 5 & 279.32 & 300 & 307 & 307 & 299.83 & 286 & 307 & 293 & 279.32 & 265.98 \\
\hline Scenario 6 & 272.65 & 307 & 299.8 & 300 & 299.83 & 286 & 314.16 & 286.16 & 299.83 & 292.67 \\
\hline Scenario 7 & 292.67 & 300 & 314.1 & 307 & 293 & 279.327 & 307 & 279.32 & 293 & 299.34 \\
\hline Scenario 8 & 286 & 286 & 299.8 & 314 & 279.32 & 286 & 299.83 & 293 & 299.83 & 299.34 \\
\hline Scenario 9 & 286 & 314 & 299.8 & 300 & 299.83 & 272.653 & 314.16 & 306.67 & 293 & 279.32 \\
\hline Scenario 10 & 292.67 & 300 & 307 & 321 & 299.83 & 286 & 299.83 & 293 & 286.16 & 279.32 \\
\hline
\end{tabular}
given in Table 2.

Table 2. Stochastic model for active power of WTs (kW). 


\subsection{Effects of Different Loop Selection on Network Reconfiguration}

In this section, we have illustrated the importance of loop selection sequence on distribution networks' loss reduction. To this end, we have implemented the best and the worst sequence of loop selection on deterministic and aggregated scenarios of networks. As demonstrated in Table 3, by selecting the best case for loops sequence, network power losses would be minimum state.

\subsection{Optimization Algorithms Comparison}

In this section, we have compared the results of TLBO algorithm with that of the PSO and GA algorithms. For this purpose, we have implemented these algorithms to the proposed distribution network in two load models: Aggregated and Deterministic scenarios. In comparison of these optimization algorithms, we have noticed to the capacity of installed capacitors, their costs and also actual power losses magnitudes in Table 4 . The branches that must be opened are brought in Table 5.

We can see from the Table 4 and 5 and also convergence curves of three algorithms in Figure 7 that TLBO algorithm has better performance compared with PSO and GA and it reaches to the best case of network configuration in less iteration than other algorithms.

Since in implementing of these scenarios to the assumed distribution network, we have applied constraint of Bus bars voltage magnitude in our simulations, so suitable configurations to the under studying distribution network is achieved. In Figure 8, the obtained profile voltage for 10 representative scenarios is shown. Also, the profile voltage of the deterministic and the aggregated scenarios is shown in Figure 9.

Table 3. Importance of sequence of loops selection.

\begin{tabular}{|c|c|c|c|c|c|c|c|c|c|c|c|}
\hline \multicolumn{6}{|c|}{ Best case } & \multicolumn{6}{|c|}{ Worst case } \\
\hline \multicolumn{3}{|c|}{$\begin{array}{l}\text { Deterministic } \\
\text { Scenario }\end{array}$} & \multicolumn{3}{|c|}{$\begin{array}{c}\text { Aggregated } \\
\text { Scenario }\end{array}$} & \multicolumn{3}{|c|}{$\begin{array}{l}\text { Deterministic } \\
\text { Scenario }\end{array}$} & \multicolumn{3}{|c|}{$\begin{array}{l}\text { Aggregated } \\
\text { Scenario }\end{array}$} \\
\hline \multicolumn{3}{|c|}{$\begin{array}{l}\text { Network loss } \\
=473.938 \mathrm{~kW}\end{array}$} & \multicolumn{3}{|c|}{$\begin{array}{l}\text { Network loss } \\
=485.098 \mathrm{~kW}\end{array}$} & \multicolumn{3}{|c|}{$\begin{array}{l}\text { Network loss } \\
=497.802 \mathrm{~kW}\end{array}$} & \multicolumn{3}{|c|}{$\begin{array}{l}\text { Network loss } \\
=507.563 \mathrm{~kW}\end{array}$} \\
\hline \multirow{2}{*}{$\begin{array}{l}\text { Sequence } \\
\text { of net- } \\
\text { work loops } \\
\text { selection }\end{array}$} & \multicolumn{2}{|c|}{$\begin{array}{c}\text { Branches } \\
\text { that must be } \\
\text { opened }\end{array}$} & \multirow{2}{*}{$\begin{array}{c}\text { Sequence } \\
\text { of network } \\
\text { loops } \\
\text { selection }\end{array}$} & \multicolumn{2}{|c|}{$\begin{array}{c}\text { Branches } \\
\text { that must be } \\
\text { opened }\end{array}$} & \multirow{2}{*}{$\begin{array}{l}\text { Sequence } \\
\text { of net- } \\
\text { work loops } \\
\text { selection }\end{array}$} & \multicolumn{2}{|c|}{$\begin{array}{c}\text { Branches } \\
\text { that must be } \\
\text { opened }\end{array}$} & \multirow{2}{*}{$\begin{array}{l}\text { Sequence } \\
\text { of net- } \\
\text { work loops } \\
\text { selection }\end{array}$} & \multicolumn{2}{|c|}{$\begin{array}{c}\text { Branches that must } \\
\text { be opened }\end{array}$} \\
\hline & from & to & & from & to & & from & to & & from & to \\
\hline Tie12 & 84 & $\mathrm{~J} 33$ & Tie3 & 34 & 35 & Tie9 & $\mathrm{J} 22$ & $\mathrm{~J} 23$ & Tie1 & 55 & J13 \\
\hline Tie1 & \multicolumn{2}{|c|}{ Tie1 } & Tie12 & 84 & $\mathrm{~J} 33$ & Tie8 & $\mathrm{J} 28$ & $\mathrm{~J} 29$ & Tie10 & & \\
\hline Tie13 & 13 & $\mathrm{~J} 3$ & Tie13 & 13 & $\mathrm{~J} 3$ & Tie4 & 25 & J9 & Tie7 & 90 & $\mathrm{~J} 34$ \\
\hline Tie5 & 94 & $\mathrm{~J} 36$ & Tie11 & \multicolumn{2}{|c|}{ Tie11 } & Tie3 & 34 & 35 & Tie6 & 85 & $\mathrm{~J} 37$ \\
\hline Tie9 & $\mathrm{J} 22$ & $\mathrm{~J} 23$ & Tie8 & 73 & $\mathrm{~J} 29$ & Tie13 & 45 & $\mathrm{~J} 15$ & Tie13 & 45 & $J 15$ \\
\hline Tie10 & J19 & $\mathrm{J} 20$ & Tie1 & \multicolumn{2}{|c|}{ Tie1 } & Tie10 & \multicolumn{2}{|c|}{ Tie10 } & Tie5 & 94 & $\mathrm{~J} 36$ \\
\hline Tie6 & \multicolumn{2}{|c|}{ Tie6 } & Tie4 & 25 & J9 & Tie7 & 92 & $\mathrm{~J} 35$ & Tie12 & $\mathrm{J} 30$ & $\mathrm{~J} 31$ \\
\hline Tie3 & 34 & 35 & Tie10 & J19 & $\mathrm{J} 20$ & Tie2 & 65 & $\mathrm{~J} 27$ & Tie2 & \multicolumn{2}{|c|}{ Tie2 } \\
\hline Tie8 & 73 & $\mathrm{~J} 29$ & Tie6 & 87 & $\mathrm{~J} 37$ & Tie5 & 94 & $\mathrm{~J} 36$ & Tie4 & 25 & J9 \\
\hline Tie7 & $\mathrm{J} 34$ & $\mathrm{~J} 35$ & Tie7 & $\mathrm{J} 34$ & $\mathrm{~J} 35$ & Tie12 & 84 & $\mathrm{~J} 33$ & Tie3 & 34 & 35 \\
\hline Tie4 & 25 & J9 & Tie2 & 65 & $\mathrm{~J} 27$ & Tie1 & \multicolumn{2}{|c|}{ Tie1 } & Tie8 & 73 & J29 \\
\hline Tie2 & 65 & $\mathrm{~J} 27$ & Tie5 & \multicolumn{2}{|c|}{ Tie5 } & Tie6 & 87 & J37 & Tie11 & & \\
\hline Tie11 & \multicolumn{2}{|c|}{ Tie11 } & Tie9 & $\mathrm{J} 22$ & $\mathrm{~J} 23$ & Tie11 & & & Tie9 & $\mathrm{J} 22$ & $\mathrm{~J} 23$ \\
\hline
\end{tabular}


Table 4. Comparison of three algorithms.

\begin{tabular}{|l|c|c|c|c|c|c|}
\hline Optimization algorithm & \multicolumn{2}{|c|}{ TLBO } & \multicolumn{2}{c|}{ PSO } & \multicolumn{2}{c|}{ GA } \\
\hline Network model & $\begin{array}{c}\text { Aggregated } \\
\text { scenario }\end{array}$ & $\begin{array}{c}\text { Deterministic } \\
\text { scenario }\end{array}$ & $\begin{array}{c}\text { Aggregated } \\
\text { scenario }\end{array}$ & $\begin{array}{c}\text { Deterministic } \\
\text { scenario }\end{array}$ & $\begin{array}{c}\text { Aggregated } \\
\text { scenario }\end{array}$ & $\begin{array}{c}\text { Deterministic } \\
\text { scenario }\end{array}$ \\
\hline Installed cap. (MVAr) & 7.715 & 6.3 & 7.945 & 6.415 & 8.335 & 6.655 \\
Cap. Cost (\$) & 10637.7 & 8875 & 10930.9 & 9059.8 & 11415.5 & 9371 \\
Actual power losses (kW) & 485.098 & 473.938 & 485.34 & 473.9 & 486.258 & 474.035 \\
Total cost & $\mathbf{6 6 7 6 0 3 . 8 6 8 4}$ & $\mathbf{6 5 0 7 2 7 . 3 8 6 8}$ & $\mathbf{6 6 8 2 2 4 . 6 8 2 1}$ & 650860.4253 & 669952.6248 & 651354.6678 \\
\hline
\end{tabular}

Table 5. Branches that should be open by three algorithms.

\begin{tabular}{|c|c|c|c|c|c|c|c|c|c|c|c|}
\hline \multicolumn{4}{|c|}{ GA } & \multicolumn{4}{|c|}{ PSO } & \multicolumn{4}{|c|}{ TLBO } \\
\hline \multicolumn{2}{|c|}{$\begin{array}{l}\text { Deterministic } \\
\text { scenario }\end{array}$} & \multicolumn{2}{|c|}{$\begin{array}{l}\text { Aggregated } \\
\text { scenario }\end{array}$} & \multicolumn{2}{|c|}{$\begin{array}{c}\text { Deterministic } \\
\text { scenario }\end{array}$} & \multicolumn{2}{|c|}{$\begin{array}{c}\text { Aggregated } \\
\text { scenario }\end{array}$} & \multicolumn{2}{|c|}{$\begin{array}{l}\text { Deterministic } \\
\text { scenario }\end{array}$} & \multicolumn{2}{|c|}{ Aggregated scenario } \\
\hline from & to & from & to & from & to & from & to & from & to & from & to \\
\hline 34 & 35 & 84 & $\mathrm{~J} 33$ & 34 & 35 & 34 & 35 & 85 & $\mathrm{~J} 37$ & 34 & 35 \\
\hline 25 & J9 & 25 & J9 & 84 & $\mathrm{~J} 33$ & \multicolumn{2}{|c|}{ Tie11 } & 65 & $\mathrm{~J} 27$ & 84 & J33 \\
\hline 84 & $\mathrm{~J} 33$ & 85 & $\mathrm{~J} 33$ & 85 & $\mathrm{~J} 33$ & 94 & $\mathrm{~J} 63$ & 84 & $\mathrm{~J} 33$ & 13 & $\mathrm{~J} 3$ \\
\hline $\mathrm{J} 22$ & $\mathrm{~J} 23$ & 34 & 35 & \multicolumn{2}{|c|}{ Tie1 } & 84 & $\mathrm{~J} 33$ & 34 & 35 & \multicolumn{2}{|c|}{ Tie11 } \\
\hline 13 & $\mathrm{~J} 3$ & J19 & $\mathrm{J} 20$ & \multicolumn{2}{|c|}{ Tie2 } & 13 & $\mathrm{~J} 3$ & 73 & $\mathrm{~J} 29$ & 73 & $\mathrm{~J} 29$ \\
\hline 90 & $\mathrm{~J} 34$ & $\mathrm{~J} 22$ & $\mathrm{~J} 23$ & 73 & $\mathrm{~J} 29$ & 25 & J9 & 13 & $\mathrm{~J} 3$ & & \\
\hline \multirow[t]{3}{*}{96} & 97 & \multicolumn{2}{|c|}{ Tie1 } & $\mathrm{J} 34$ & $\mathrm{~J} 35$ & \multicolumn{2}{|c|}{ Tie1 } & \multicolumn{2}{|c|}{ Tie11 } & 25 & J9 \\
\hline & Tie11 & $\mathrm{J} 34$ & $\mathrm{~J} 35$ & $\mathrm{~J} 22$ & $\mathrm{~J} 23$ & 73 & J29 & 95 & 96 & J19 & $\mathrm{J} 20$ \\
\hline & Tie2 & 13 & $\mathrm{~J} 3$ & 13 & $\mathrm{~J} 3$ & \multicolumn{2}{|c|}{ Tie6 } & \multicolumn{2}{|c|}{ Tie1 } & 87 & $\mathrm{~J} 37$ \\
\hline \multirow[t]{2}{*}{73} & $\mathrm{~J} 29$ & 73 & $\mathrm{~J} 29$ & J19 & $\mathrm{J} 20$ & \multicolumn{2}{|c|}{ Tie2 } & J19 & $\mathrm{J} 20$ & J34 & $\mathrm{J} 35$ \\
\hline & Tie6 & 80 & $\mathrm{~J} 30$ & \multicolumn{2}{|c|}{ Tie11 } & \multicolumn{2}{|c|}{ Tie7 } & $\mathrm{J} 22$ & $\mathrm{~J} 23$ & 65 & $\mathrm{~J} 27$ \\
\hline \multirow[t]{2}{*}{ J19 } & $\mathrm{J} 20$ & 65 & $\mathrm{~J} 27$ & 25 & J9 & J19 & $\mathrm{J} 20$ & 25 & J9 & \multicolumn{2}{|c|}{ Tie5 } \\
\hline & & & & 80 & $\mathrm{~J} 30$ & $\mathrm{~J} 22$ & $\mathrm{~J} 23$ & J34 & J35 & $\mathrm{J} 22$ & $\mathrm{~J} 23$ \\
\hline
\end{tabular}

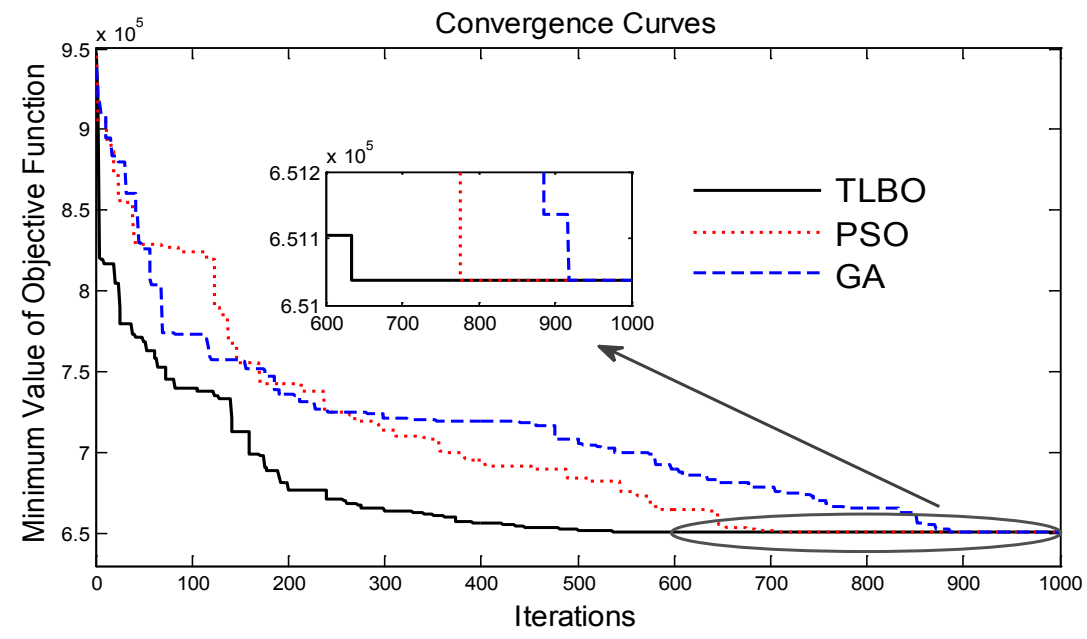

Figure 7. Convergence curves for the proposed three optimization algorithms. 


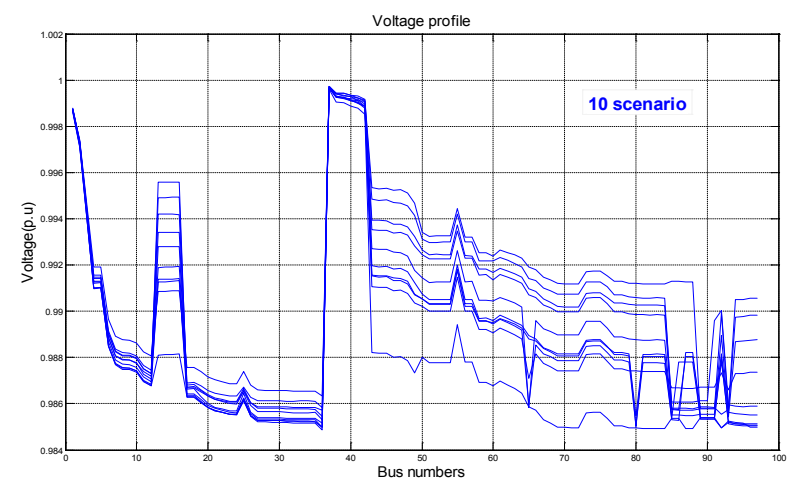

Figure 8. Voltage profile for 10 scenarios.

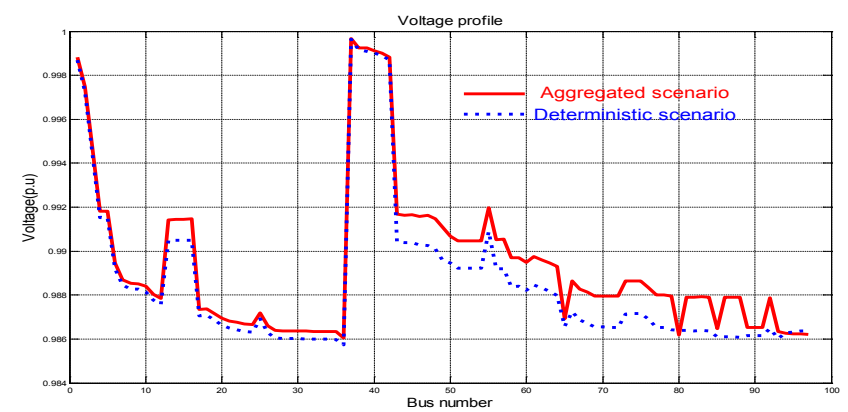

Figure 9. Voltage profile for aggregated and deterministic scenarios.

Table 6. Results of scenarios.

\begin{tabular}{|c|c|c|c|c|c|c|c|c|c|c|c|}
\hline \multicolumn{6}{|c|}{ Best case } & \multicolumn{6}{|c|}{ Worst case } \\
\hline \multicolumn{3}{|c|}{ Deterministic Scenario } & \multicolumn{3}{|c|}{ Aggregated Scenario } & \multicolumn{3}{|c|}{ Deterministic Scenario } & \multicolumn{3}{|c|}{ Aggregated Scenario } \\
\hline \multicolumn{3}{|c|}{ Network loss $=473.938 \mathrm{~kW}$} & \multicolumn{3}{|c|}{ Network loss $=485.098 \mathrm{~kW}$} & \multicolumn{3}{|c|}{ Network loss $=497.802 \mathrm{~kW}$} & \multicolumn{3}{|c|}{ Network loss $=\mathbf{5 0 7 . 5 6 3 \mathrm { kW }}$} \\
\hline \multirow{2}{*}{$\begin{array}{l}\text { Sequence } \\
\text { of network } \\
\text { loops } \\
\text { selection }\end{array}$} & \multicolumn{2}{|c|}{$\begin{array}{l}\text { Branches that } \\
\text { must be opened }\end{array}$} & \multirow{2}{*}{$\begin{array}{c}\text { Sequence } \\
\text { of network } \\
\text { loops } \\
\text { selection }\end{array}$} & \multicolumn{2}{|c|}{$\begin{array}{c}\text { Branches } \\
\text { that must be } \\
\text { opened }\end{array}$} & \multirow{2}{*}{$\begin{array}{c}\text { Sequence } \\
\text { of network } \\
\text { loops } \\
\text { selection }\end{array}$} & \multicolumn{2}{|c|}{$\begin{array}{l}\text { Branches that } \\
\text { must be opened }\end{array}$} & \multirow{2}{*}{$\begin{array}{c}\text { Sequence } \\
\text { of network } \\
\text { loops } \\
\text { selection }\end{array}$} & \multicolumn{2}{|c|}{$\begin{array}{l}\text { Branches that } \\
\text { must be opened }\end{array}$} \\
\hline & from & to & & from & to & & from & to & & from & to \\
\hline Tie12 & 84 & $\mathrm{~J} 33$ & Tie3 & 34 & 35 & Tie9 & $\mathrm{J} 22$ & $\mathrm{~J} 23$ & Tie1 & 55 & J13 \\
\hline Tie1 & \multicolumn{2}{|c|}{ Tie1 } & Tie12 & 84 & $\mathrm{~J} 33$ & Tie8 & $\mathrm{J} 28$ & J29 & Tie10 & \multicolumn{2}{|c|}{ Tie10 } \\
\hline Tie13 & 13 & $\mathrm{~J} 3$ & Tie13 & 13 & $\mathrm{~J} 3$ & Tie4 & 25 & J9 & Tie7 & 90 & $\mathrm{~J} 34$ \\
\hline Tie5 & 94 & $\mathrm{~J} 36$ & Tie11 & \multicolumn{2}{|c|}{ Tie11 } & Tie3 & 34 & 35 & Tie6 & 85 & J37 \\
\hline Tie9 & $\mathrm{J} 22$ & $\mathrm{~J} 23$ & Tie8 & 73 & $\mathrm{~J} 29$ & Tie13 & 45 & J15 & Tie13 & 45 & $\mathrm{~J} 15$ \\
\hline Tie10 & J19 & $\mathrm{J} 20$ & Tiel & \multicolumn{2}{|c|}{ Tie1 } & Tie10 & \multicolumn{2}{|c|}{ Tie10 } & Tie5 & 94 & J36 \\
\hline Tie6 & \multicolumn{2}{|c|}{ Tie6 } & Tie4 & 25 & J9 & Tie7 & 92 & $\mathrm{~J} 35$ & Tie12 & $\mathrm{J} 30$ & $\mathrm{~J} 31$ \\
\hline Tie3 & 34 & 35 & Tie10 & J19 & $\mathrm{J} 20$ & Tie2 & 65 & $\mathrm{~J} 27$ & Tie2 & \multicolumn{2}{|c|}{ Tie2 } \\
\hline Tie8 & 73 & $\mathrm{~J} 29$ & Tie6 & 87 & $\mathrm{~J} 37$ & Tie5 & 94 & $\mathrm{~J} 36$ & Tie4 & 25 & J9 \\
\hline Tie7 & J34 & $\mathrm{J} 35$ & Tie7 & J34 & $\mathrm{J} 35$ & Tie12 & 84 & $\mathrm{~J} 33$ & Tie3 & 34 & 35 \\
\hline Tie4 & 25 & J9 & Tie2 & 65 & $\mathrm{~J} 27$ & Tie1 & \multicolumn{2}{|c|}{ Tie1 } & Tie8 & 73 & $\mathrm{~J} 29$ \\
\hline Tie2 & 65 & $\mathrm{~J} 27$ & Tie5 & \multicolumn{2}{|c|}{ Tie5 } & Tie6 & 87 & $\mathrm{~J} 37$ & Tie11 & \multicolumn{2}{|c|}{ Tie11 } \\
\hline Tie11 & \multicolumn{2}{|c|}{ Tie11 } & Tie9 & $\mathrm{J} 22$ & $\mathrm{~J} 23$ & Tie11 & $\mathrm{Ti}$ & & Tie9 & $\mathrm{J} 22$ & $\mathrm{~J} 23$ \\
\hline
\end{tabular}

Table 7. Capacitor placement for aggregated scenario.

\begin{tabular}{|l|c|c|c|c|c|c|c|c|c|c|c|c|c|}
\hline $\begin{array}{l}\text { Bus } \\
\text { No. }\end{array}$ & kVAr & $\begin{array}{l}\text { Bus } \\
\text { No. }\end{array}$ & kVAr & $\begin{array}{l}\text { Bus } \\
\text { No. }\end{array}$ & kVAr & $\begin{array}{l}\text { Bus } \\
\text { No. }\end{array}$ & kVAr & $\begin{array}{l}\text { Bus } \\
\text { No. }\end{array}$ & kVAr & $\begin{array}{l}\text { Bus } \\
\text { No. }\end{array}$ & kVAr & $\begin{array}{l}\text { Bus } \\
\text { No. }\end{array}$ & kVAr \\
\hline 2 & 70 & 18 & 70 & 32 & 200 & 44 & 70 & 58 & 50 & 73 & 300 & 85 & 170 \\
\hline 3 & 70 & 19 & 175 & 33 & 250 & 45 & 50 & 59 & 50 & 74 & 100 & 87 & 195 \\
\hline 4 & 100 & 20 & 50 & 34 & 70 & 48 & 100 & 60 & 265 & 75 & 195 & 89 & 195 \\
\hline 5 & 50 & 21 & 50 & 35 & 125 & 49 & 100 & 62 & 250 & 76 & 50 & 90 & 50 \\
\hline 6 & 50 & 24 & 100 & 37 & 125 & 50 & 70 & 63 & 70 & 77 & 50 & 91 & 225 \\
\hline 7 & 70 & 25 & 70 & 38 & 70 & 51 & 100 & 65 & 70 & 78 & 195 & 93 & 100 \\
\hline 9 & 50 & 26 & 100 & 40 & 50 & 52 & 50 & 68 & 100 & 79 & 70 & 94 & 125 \\
\hline 14 & 225 & 28 & 125 & 41 & 50 & 53 & 70 & 69 & 100 & 81 & 70 & 95 & 125 \\
\hline 15 & 125 & 29 & 175 & 42 & 70 & 54 & 70 & 71 & 275 & 82 & 70 & & \\
\hline 17 & 70 & 31 & 150 & 43 & 150 & 57 & 70 & 72 & 170 & 84 & 175 & & \\
\hline
\end{tabular}


Table 8. Capacitor placement for deterministic scenario.

\begin{tabular}{|c|c|c|c|c|c|c|c|c|c|c|c|c|c|}
\hline $\begin{array}{l}\text { Bus } \\
\text { No. }\end{array}$ & kVAr & $\begin{array}{l}\text { Bus } \\
\text { No. }\end{array}$ & kVAr & $\begin{array}{l}\text { Bus } \\
\text { No. }\end{array}$ & kVAr & $\begin{array}{l}\text { Bus } \\
\text { No. }\end{array}$ & kVAr & $\begin{array}{l}\text { Bus } \\
\text { No. }\end{array}$ & kVAr & $\begin{array}{l}\text { Bus } \\
\text { No. }\end{array}$ & kVAr & $\begin{array}{l}\text { Bus } \\
\text { No. }\end{array}$ & kVAr \\
\hline 1 & 50 & 16 & 70 & 25 & 265 & 39 & 50 & 59 & 175 & 74 & 225 & 89 & 100 \\
\hline 3 & 70 & 17 & 175 & 27 & 170 & 40 & 50 & 61 & 195 & 76 & 100 & 90 & 175 \\
\hline 4 & 70 & 18 & 50 & 28 & 50 & 46 & 175 & 64 & 50 & 77 & 70 & 91 & 250 \\
\hline 7 & 70 & 19 & 50 & 30 & 70 & 47 & 70 & 65 & 50 & 78 & 170 & 93 & 70 \\
\hline 9 & 50 & 20 & 70 & 31 & 50 & 49 & 70 & 67 & 195 & 79 & 70 & 96 & 150 \\
\hline 10 & 100 & 21 & 125 & 32 & 70 & 51 & 70 & 69 & 150 & 81 & 100 & 97 & 50 \\
\hline 11 & 175 & 22 & 70 & 35 & 175 & 53 & 125 & 71 & 70 & 82 & 195 & & \\
\hline 12 & 50 & 23 & 70 & 37 & 70 & 56 & 50 & 72 & 50 & 84 & 50 & & \\
\hline 15 & 50 & 24 & 250 & 38 & 125 & 57 & 150 & 73 & 50 & 85 & 70 & & \\
\hline
\end{tabular}

By comparing the obtained results in Tables 3, 6-8 and also Figure 8 and 9 , it is obvious that there are difference between the results of deterministic scenario, ten representative scenarios and aggregated scenario. In addition, the probability of the deterministic scenario is about $4.4 \%$ (among 1000 produced scenarios). This means that the deterministic solution may happen with the low probability of $4.4 \%$. Consequently, the deterministic scenario cannot be an acceptable solution by itself. On the other hand, using the obtained representative scenarios, all 10 scenarios contribute into determining the DNR results according to their probability values. The 10 representative scenarios totally capture about $10.6 \%$ of the uncertainty spectrum of the wind speed, which is about 2.5 times of the deterministic scenario. So, the DFR results of the stochastic framework are more realistic than the deterministic one. It should be noted that it can be more than $10.6 \%$, considering more scenarios, but with the cost of higher computation burden. Based on the above expression, there is a trade-off between computation burden and model reality. In this case, the number of representative scenarios will be selected based on decision maker priority. Additionally, the most important advantage of scenario aggregation is that individual scenarios' problems become simple to interpret and with aggregation the representative scenarios the underlying problem structure is preserved.

\section{Conclusion}

In this paper, the network reconfiguration algorithm which was proposed in ${ }^{13}$ has been improved by optimization of the loops selection sequence. Moreover, a joint optimization algorithm has been proposed for combination of the capacitor placement and the improved network reconfiguration. This is due to the inherent coupling relationship between these methods, and therefore, simultaneous implementation of them is more effective than considering them separately. For more practical application of the proposed method, stochastic nature of loads and wind turbine generators of network have been considered. TLBO algorithm has been employed for the proposed joint optimization problem and its results have been compared to the PSO and GA. The objective function has been proposed for minimizing the total cost due to capacitor placement and energy losses during 2 years with considering the constraints of bus voltages and the current carrying capacity of conductors. The obtained results confirmed the effectiveness of the proposed method.

\section{References}

1. Rajaji L. Neural Network Controller Based Induction Generator for Wind Turbine Applications, Indian Journal of Science and Technology. 2009; 2(2):70-74.

2. Maaref M. A Reliability Model for a Doubly Fed Induction Generator Based Wind Turbine Unit Considering Auxiliary Components, Indian Journal of Science and Technology. 2013; 6(9):5281-88.

3. Hosseini SA. Optimal Sizing and Siting Distributed Generation Resources using a Multi objective Algorithm, Turkish Journal of Electrical Engineering and Computer Sciences. 2013; 21(3):825-50.

4. Basha Shaik J. Application of Power Matrix Technique for Controlling DFIG Wind Turbine System, Indian Journal of Science and Technology. 2015; 8(23):1-5. 
5. Izadbakhsh M. Dynamic Analysis of PMSG Wind Turbine under Variable Wind Speeds and Load Conditions in the Grid Connected Mode, Indian Journal of Science and Technology. 2015; 8(14):1-7.

6. Levitin G. Optimal Capacitor Allocation in Distribution Systems using a Genetic Algorithm and a Fast Energy Loss Computation Technique, IEEE Transactions on Power Delivery. 2000; 15(2):623-28.

7. Hosseini SA. Installing Distributed Generation Units and Capacitors Simultaneously in a Distribution System Considering Economic Issues, Journal of Renewable and Sustainable Energy. 2014; 6(2):1-16.

8. Vulasala SSG, Thiruveedula S. Feeder Reconfiguration for Loss Reduction in Unbalanced Distribution System using Genetic Algorithm, International Journal of Electrical and Electronics Engineering. 2009; 3(2):240-48.

9. Lopez E. Online Reconfiguration Considering Variability Demand: Applications to Real Networks, IEEE Transactions on Power Systems. 2004; 19(1):549-53.

10. Young-Jae J. An Efficient Simulated Annealing Algorithm for Network Reconfiguration in Large-Scale Distribution Systems, IEEE Transactions on Power Delivery. 2002; 17(4):1070-78.

11. Su CT, Lee CS. Feeder Reconfiguration and Capacitor Setting for Loss Reduction of Distribution Systems, Electric Power Systems Research. 2001; 58(2):97-102.

12. Zeng R. Reconfiguration and Capacitor Placement for Loss Reduction of Distribution System, IEEE Region 10 Conference on Computers, Communications, Control and Power Engineering. 2008; 23(4):1747-55.
13. Guimaraes MAN. Distribution Systems Operation Optimisation through Reconfiguration and Capacitor Allocation by a Dedicated Genetic Algorithm, IET Generation, Transmission and Distribution. 2010; 4(11):1213-22.

14. Zhang D. Joint Optimization for Power Loss Reduction in Distribution Systems, IEEE Transactions on Power Systems. 2008; 23(1):161-69.

15. Chang CF. Reconfiguration and Capacitor Placement for Loss Reduction of Distribution Systems by Ant Colony Search Algorithm, IEEE Transactions on Power Systems. 2008; 23(4):1747-55.

16. Santosh J. Teaching Learning Based Optimization (TLBO) for Optimal Placement of Piezo-Patches, Indian Journal of Science and Technology. 2016; 9(34):1-5.

17. Rao RV. Teaching-Learning-Based Optimization: An Optimization Method for Continuous Non-Linear Large Scale Problems, Information Sciences. 2012; 183(1):1-15.

18. Papoulis A. Probability, Random Variables, and Stochastic Processes 3rd Edition. Boston, USA: McGraw-Hill, 1991.

19. Damousis IG. A Solution to the Unit-Commitment Problem using Integer-Coded Genetic Algorithm, IEEE Transactions on Power Systems, 2004; 19(2):1165-72.

20. Gallego RA. Optimal Capacitor Placement in Radial Distribution Networks, IEEE Transactions on Power Systems. 2001; 16(4):630-37.

21. Ng HN, Salama MMA, Chikhani AY. Classification of Capacitor Allocation Techniques, IEEE Transactions on Power Delivery. 2000; 15(1). 387-92. 